\title{
A COOPERAÇÃO INTERNACIONAL COMO DÁDIVA. ALGUMAS APROXIMAÇÕES
}

Kelly Cristiane da Silva

As sociedades progrediram na medida em que elas mesmas, seus subgrupos [...] aprenderam a estabilizar suas relações, a dar, a receber e, enfim, a retribuir. Para comerciar foi preciso primeiro depor as lanças. [...] Foi somente depois que as pessoas aprenderam a criar e a satisfazer interesses mutuamente e, enfim, a defendê-los sem terem que recorrer às armas. Foi assim que o clã, a tribo, os povos aprenderam - e é assim que, amanhã, em nosso mundo civilizado, as classes e as nações, bem como os indivíduos devem aprender a opor-se sem massacrar-se e a dar-se sem sacrificar-se uns aos outros (Mauss 1974).

A assistência às vítimas de fenômenos naturais com grande capacidade de destruição, como os tsunamis no sul da Ásia e os furacões que devastaram amplas áreas do Golfo do México, tem colocado a dinâmica da AID (Assistence for International Development) como importante ponto de pauta na mídia internacional. Aparentemente, Estados-nações, instituições multilaterais, organismos não-governamentais locais e internacionais, entre outros, somam esforços em auxílio a milhares de pessoas afetadas por essas catástrofes.

Em janeiro de 2005, as Nações Unidas destacaram a excepcionalidade da resposta mundial ao apelo de ajuda emergencial para os países afetados pelos tsunamis ao redor do Índico: em reunião realizada em Genebra, teriam sido captados 70\% dos US\$ 977 milhões solicitados pela ONU (ONU 2005). A configuração deste cenário, contudo, não foi propriamente espontânea. Ele se constituiu após o pronunciamento do então chefe de operações de assistência da ONU, Jan Egeland, em 27 de dezembro de 2004, quando os países ricos foram acusados de sovinas. Até então os EUA, por exemplo, tinham declarado a disponibilização de apenas US\$ 15 milhões. Aos poucos, vimos instalar-se entre os doadores uma verdadeira competição pela posição de maior doador, expressa nos diferentes rankings que eram divulgados pela 
imprensa a cada dia sobre o volume de recursos arrecadados para o auxílio às vítimas. Depois de o Japão ter declarado a oferta de US\$ 500 milhões para doação, a Alemanha comprometeu-se a destinar US\$ 674 milhões para tanto. No dia seguinte, contudo, ela perdeu sua posição de liderança para a Austrália, que afirmava colocar à disposição dos países afetados e dos organismos de ajuda um total de US\$ 765 milhões. Nesse contexto, os EUA aumentaram sua ajuda inicial de 15 para US\$ 350 milhões (Governos 2005).

Em setembro de 2005, foi a vez de os EUA colocarem-se na posição de receptores da assistência internacional. A comoção diante dos estragos causados pelos furacões Katrina e Rita catalizou a disponibilização de vários tipos de recursos aos EUA: em 11 de setembro, o total da ajuda arrecadada era já de US\$ 739 milhões (Grupos 2005). Mesmo Estados muito pobres, como Bangladesh, República Dominicana, Sri Lanka, entre outros, doaram recursos. No entanto, os EUA não aceitaram todas as ofertas de ajuda. Os 1.500 médicos colocados à disposição pelo Estado cubano foram rejeitados, bem como a oferta de combustível abaixo do preço de mercado realizada pela Venezuela. Cuba, por sua vez, também negou uma ajuda de US\$50.000 dos EUA quando o país foi afetado pelo furacão Dennis.

Este artigo toma como objeto de discussão as políticas de doação entre Estados-nações executadas por diferentes agentes que atuam no campo da assistência ao desenvolvimento internacional (AID) e da ajuda humanitária. Este problema é aqui abordado através de um estudo de caso. Analiso como tais políticas se configuravam e eram experimentadas pela comunidade de doadores em Timor-Leste entre 2002 e 2003. ${ }^{1}$ A partir deste caso, discutido à luz do regime da dádiva (Mauss 1974), espero trazer à tona dimensões pouco exploradas sobre o que está em jogo nessas práticas: estratégias de definição de status político e cultivo de identidades nacionais por parte de diferentes doadores, com a conseqüente delimitação de relações de precedência entre eles em arenas glocalizadas de negociação e de construção de hegemonia.

Obviamente, não se trata de negar que a ajuda humanitária e a assistência ao desenvolvimento sejam veículos privilegiados de política internacional por parte dos países doadores, expressão de interesses explícitos e implícitos (Mason 1964). Há mais de um século, Mauss (1974) já apontava que a dádiva é uma estratégia de gestão de relações de poder. É preciso observar, contudo, que não só interesses comerciais ou de subjugação política orientam a ação dos atores nesse campo, mas também táticas relacionadas à construção de vínculos de identidade, aliança e honra entre eles. O que analiso ao longo do texto são alguns dos meios através dos quais estes objetivos são negociados e alcançados. 
O texto está dividido em três seções, além da conclusão. Em um primeiro momento, contextualizo o caso timorense no cenário internacional e algumas dimensões do paradigma da dádiva, tal como formulado primeiramente por Marcel Mauss (1974) e, contemporaneamente, por certos integrantes do Movimento Anti-utilitarista nas Ciências Sociais (M.A.U.S.S.), em especial Godbout (1999) e Caillé (2002).

Na segunda parte, mergulho na análise da Reunião de Timor-Leste com os Parceiros do Desenvolvimento (RTLPD), ocorrida em maio de 2003. A RTLPD aqui abordada é uma variação do tipo genérico de evento característico do campo da AID, denominado de conferência de doadores, do qual tomam parte as diferentes entidades que compõem este campo - Banco Mundial, Nações Unidas, agências de cooperação bilateral e os beneficiários da AID, entre outros. As conferências de doadores são fenômenos rituais no universo da assistência internacional. São, por isso, manifestações condensadas e expressivas de seu repertório simbólico e modo de funcionamento. Na qualidade de um ritual, a reunião é uma ocasião solene na qual são renovados alguns dos valores e das instituições que fazem operar este campo. ${ }^{2}$ Utilizo-a como âncora para expandir certas reflexões a respeito dos significados e das implicações das políticas de doação internacional.

Na terceira seção do artigo, tais implicações são exploradas por meio da discussão de fatos e processos envolvidos na preparação da reunião, com destaque para as políticas de construção de capacidades que se constituem, contemporaneamente, veículos fundamentais de política externa por parte de Estados-nações doadores. No contexto etnográfico abordado, os programas de construção ou desenvolvimento de capacidades são os objetos privilegiados de doação. Daí o potencial cognitivo da análise dos mesmos. Por fim, nas considerações finais, sintetizo os argumentos propostos ao longo do texto e caracterizo a natureza da contradádiva ofertada por Timor-Leste aos doadores.

Os dados analisados a seguir foram produzidos ao longo de 11 meses de trabalho de campo em Timor-Leste, entre 2002 e 2003. Nesse período, trabalhei como voluntária na Unidade de Coordenação de Desenvolvimento de Capacidades (UCDC), órgão vinculado ao Gabinete do Primeiro-Ministro, e que tem por função captar, articular e monitorar os fluxos de assistência técnica internacional direcionados à qualificação das instituições de Estado. Esta inserção institucional na administração pública permitiu-me uma interação cotidiana privilegiada com os doadores e com a elite do funcionalismo local, em espaços formais e informais, bem como o acesso a eventos bastante reservados, dos quais a conferência ora discutida é o melhor exemplo. 


\section{Timor-Leste, seus parceiros do desenvolvimento e a dádiva}

Timor-Leste é o mais novo país do mundo. É também o mais recente membro das Nações Unidas, cujo processo de construção do Estado tem sido considerado exemplar por certa parcela da comunidade internacional. Em 2002, a independência de Timor-Leste, proclamada unilateralmente em 1975, foi restaurada depois de aproximadamente 430 anos de colonização portuguesa, 24 anos de ocupação indonésia e 30 meses de administração transitória das Nações Unidas. Desde os últimos meses de 1999, os recursos doados pela assistência internacional têm sido responsáveis por parte significativa dos técnicos, dos equipamentos e do orçamento que, ao longo do tempo, têm permitido a criação e a manutenção da incipiente administração pública do país, bem como a prestação de serviços e auxílio emergencial à população. ${ }^{3}$ Os bens ofertados podem ser classificados em três espécies: recursos financeiros, humanos e tecnológicos. Os primeiros são depositados em diferentes fundos ou podem ser imediatamente direcionados para o orçamento da República Democrática de Timor-Leste (RDTL). ${ }^{4}$ Os demais são distribuídos pelo aparelho do Estado em resposta a projetos e acordos bi ou multilaterais de desenvolvimento e cooperação.

São denominados parceiros do desenvolvimento os Estados-nações e seus respectivos órgãos de cooperação internacional, agências do Sistema ONU, missões de instalação e manutenção de paz das Nações Unidas, organizações não-governamentais internacionais, instituições financeiras internacionais (Fundo Monetário Internacional, Banco Mundial, Banco Asiático de Desenvolvimento), instituições religiosas etc. que, a fundo perdido, repassam recursos ao Estado da República Democrática de Timor-Leste (RDTL). Os recursos que têm como origem os parceiros do desenvolvimento são nominalmente depositados em nome de Timor-Leste na qualidade de doações, pelo que esses atores são também denominados de doadores.

O sistema de doação internacional pode ser tomado como um fato social total quando tratamos de analisar o processo de formação do Estado timorense, isto é, ele "põe em movimento [...] a totalidade da sociedade e suas instituições [...]" (Mauss 1974:179). Ele está implicado em todas as faces e fases desse empreendimento, condicionando fenômenos tão diversos como a consolidação das línguas nacionais, a definição dos modelos de orçamento adotados pelo Estado, a construção da legislação que define o funcionamento da administração, entre muitos outros exemplos. Até 2003, cerca de três quartos das despesas públicas do Estado eram pagas com recursos depositados em nome de Timor-Leste pelos doadores. ${ }^{5}$ 
Entre os representantes dos doadores lotados em Timor-Leste, o repasse "gratuito" de recursos ao Estado local é publicamente justificado com base em argumentos de solidariedade e compromisso social. Organizações não-governamentais que monitoram esse campo aventam, porém, que o interesse político e econômico é o que alimenta a cooperação. Sugiro contudo que, para além dessas motivações, a obrigação de dar e algumas de suas implicações são forças de peso para a constituição deste campo. A Timor-Leste (e a qualquer outro país altamente dependente da AID) cabe a obrigação de receber e o peso da dívida contraída, embora os recursos sejam ofertados como fundos perdidos. Nesse sentido, estamos falando aqui não de uma dívida monetária, mas de um penhor moral que colocaria o Estado timorense, de certa forma, em uma condição de subserviência a interesses estrangeiros. Daí o poder heurístico da chamada lógica da dádiva. A sobreposição, muitas vezes caótica, de projetos de ajuda humanitária e de desenvolvimento existente em Timor-Leste e em outras partes do mundo é um indicador de que a força da obrigação de dar muitas vezes se impõe à gestão racional da AID (cf. Hancock 1989).

Não argumento que o campo da cooperação técnica internacional em operação em Timor-Leste funcione exatamente nos mesmos moldes dos sistemas de trocas de sociedades melanésias ou indígenas do norte da América, tal como retratados por Mauss (1974). O que me parece interessante é resgatar as interpretações atribuídas pelo autor, e posteriormente expandidas por alguns componentes do M.A.U.S.S., a alguns episódios, na medida em que se apresentam úteis para revelar dimensões pouco exploradas da dinâmica das relações entre as instituições que compõem a rede de doadores para Timor-Leste.

Mauss (idem) indica que a dádiva é constituída basicamente por três tipos de obrigações: dar, receber e retribuir. Na tentativa de compreender o que está implicado em cada uma das fases desse fenômeno, ele identifica que, no processo de troca, pessoas, instituições e coisas se confundem e que os objetos intercambiados têm grande força ou efeito moral: eles seriam animados por uma espécie de espírito (o hau ou o mana do doador) que, entre outras coisas, faz com que eles retornem aos seus lugares de origem. Além disso, seriam expressão da identidade do doador ou da entidade por ele representada. O Kula discutido por Malinowski (1978), assim como os potlatchs analisados por Mauss são ainda instrumentos eficazes de hierarquização social, definidores de posições de precedência e honra dos sujeitos uns diante dos outros. Nesse sentido, é possível dizer que os sistemas de troca em discussão são meios de exercício e construção de poder, fatos através dos quais se definem relações políticas. São ainda portadores de 
uma etiqueta própria, na qual o respeito ao tempo para o oferecimento da contradádiva é regra importante.

Caillé (2002), na esteira do legado de Lévi-Strauss (1982), aponta que a dádiva é um instrumento de construção de alianças. Nos termos de Godbout (1999), o dom, na economia política da dádiva, é um bem a serviço dos vínculos sociais. Daí negar-se à troca ser também uma negação à interação. Ambos os autores destacam que dádiva não é sinônimo de ausência de interesse. Em outros termos, dádiva não é sinônimo de doação gratuita. O que está implicado no dom é uma estratégia de constituição e cultivo das identidades dos sujeitos que trocam (Caillé 2002:72).

O registro moral da dádiva seria ainda informado pela coexistência de dois pares de motivações, cujos termos são contraditórios entre si: 1. interesse e desinteresse; 2 . obrigação e liberdade. Disso advém o potencial heurístico do que Caillé (ib.idem) chama de paradigma da dádiva, embora Mauss nunca tenha sistematizado suas análises nestes termos. As categorias explicativas construídas por Mauss para dar sentido a essas modalidades de troca apontavam para a variabilidade e a ambigüidade das motivações que lhes davam existência: elas eram interessadas e desinteressadas ao mesmo tempo; praticadas em função de uma obrigação livre. Mauss teria assim proposto uma perspectiva multidimensional (Caillé, idem) e polivalente (Godbout, idem) da ação. Aliás, não é por outro motivo que o Kula e demais sistemas de troca analisados por Mauss podem ser denominados de fatos sociais totais: neles estão envolvidas diferentes instituições sociais, as quais impõem à ação motivações e sentidos variados e sobrepostos.

No regime da dádiva, ${ }^{6}$ o valor atribuído aos bens trocados é sempre contextual: está ligado à identidade de quem recebe e de quem dá. É importante notar, inclusive, que Godbout (ib.idem) sugere que os bens que circulam na economia do dom sejam mensurados através de uma unidade específica, distinta das idéias de valor de uso e valor de troca: o valor de vínculo. Este seria produto da capacidade do presente em expressar, veicular e alimentar relações sociais; harmoniosas ou conflituosas, igualitárias ou hierárquicas.

\section{A Reunião de Timor-Leste com os Parceiros do Desenvolvimento}

A gestão da assistência externa em Timor-Leste é realizada através de várias modalidades de atividades: reuniões individuais com cada doador, lançamento de apelos de cooperação para projetos específicos de desenvolvimento, diálogos estratégicos de cooperação, missões de avaliação de projetos, monitoramento de disponibilização de recursos, prestação de contas etc. 
A Reunião de Timor-Leste com os Parceiros do Desenvolvimento (RTLPD), também denominada de Conferência dos Doadores, é promovida pelo governo de Timor-Leste e pela seção local do Banco Mundial.7,8

A RTLPD é um ritual periódico. De 1999 até maio de 2004, ela acontecia a cada seis meses. A partir de então passou a ocorrer uma vez ao ano. Do ponto de vista do Estado timorense, a reunião é um espaço para prestação de contas do governo aos doadores e, ao mesmo tempo, para troca de informações a respeito da condução de projetos de desenvolvimento no país. Nela, através de uma etiqueta própria, doadores e governo consolidam sua parceria para o processo de construção do Estado e o desenvolvimento do país.

A conferência é organizada em diferentes sessões, as quais formalmente respondem a objetivos específicos. Na abertura, o discurso presidencial, seguido dos comentários do Representante Especial do Secretário Geral da ONU (SRSG) em Timor-Leste, é o principal evento. A reunião segue através dos seguintes passos, organizados em sessões distintas: 1. prestação de contas dos trabalhos realizados pelo governo desde a última reunião e apresentação de estratégias para implementação futura do Plano de Desenvolvimento Nacional (PDN); 2. análise da mobilização e da utilização de recursos disponibilizados pelos doadores e perspectivas futuras; e 3. discussão do panorama de parcerias - leia-se recursos a serem doados - para implementação dos programas do PDN para o semestre seguinte. Embora cada sessão tenha objetivos próprios, a análise do conjunto das atuações do Estado timorense, por um lado, e dos parceiros do desenvolvimento, de outro, indica a repetição de certas formas discursivas, as quais revelam funções não explicitadas deste ritual.

Para efeito de análise, privilegia-se a atuação dos países doadores porque são eles, em última instância, as instituições que mantêm todo campo da AID intergovernamental em ação, sustentando, inclusive, as Nações Unidas. À medida que avançarmos, será necessário esclarecer alguns dos procedimentos envolvidos na preparação do evento, os quais indicarão com maior precisão o que está em jogo neste ritual e na dinâmica da AID como um todo.

\section{A evocação da dádiva}

Com exceção da abertura, a dinâmica de trabalho da reunião é organizada da seguinte forma: cada sessão é iniciada com uma apresentação do presidente da mesa, que comunica aos convidados os objetivos das atividades que serão realizadas naquele momento. ${ }^{9}$ Passa-se então a palavra a um representante 
do governo, cujo discurso é seguido da alocução de agências de cooperação com grande legitimidade internacional: Nações Unidas, Fundo Monetário Internacional, Banco Mundial e Programa das Nações Unidas para o Desenvolvimento (PNUD). Posteriormente, dá-se espaço para manifestação dos demais doadores. Antes de apontarmos as formas estruturais dos discursos apresentados por estes atores, vejamos o conteúdo de suas manifestações na primeira parte da reunião de maio de 2003.

A primeira sessão da conferência, intitulada Desenvolvimento desde a Última Reunião e Planos para Implementação do Plano Nacional de Desenvolvimento, foi presidida por José Ramos Horta, então ministro dos Negócios Estrangeiros e Cooperação, laureado com o Prêmio Nobel da Paz em 1992. Compuseram ainda a mesa diretiva o Primeiro-Ministro da RDTL, o representante especial adjunto do secretário- geral (DSRSG) da ONU em Timor-Leste e o vice-presidente do Banco Mundial para Sudeste da Ásia e Pacífico.

Primeiramente, submeteu-se a agenda proposta à aprovação dos parceiros do desenvolvimento. Mari Bin Alkatiri, à época Primeiro-Ministro da RDTL, recebeu a palavra. Ele indicou aos seus interlocutores o que vinha sendo realizado pelo governo com os recursos ofertados pelos doadores e os prováveis cenários futuros para o país, considerando a retirada progressiva da comunidade internacional. Seu discurso foi em português, proferido em um registro de prestação de contas.

[...] Como é de vosso conhecimento, assumimos a direção deste país com pouca experiência de governação. A agravar, recebemos um país que, como Estado, estava vazio de memória e carente de competências, de disciplina, e de vida e cultura institucionais. Mas fomos capazes de, passo a passo, desenvolver o planeamento das nossas atividades, criar instituições e capacitar os nossos quadros. Temos ainda muito por fazer. Iniciamos a implementação das atividades planeadas. Progressos consideráveis foram feitos no domínio institucional e da capacitação. Mas reconhecemos que conseguimos progressos modestos na implementação de um plano de prestação de serviços. Muito trabalho e tempo serão ainda necessários para melhorar o nosso desempenho. Por isso o vosso contínuo apoio e assistência ainda permanecem indispensáveis.

Alkatiri abordou ainda temas como economia e emprego; segurança e estabilidade; desenvolvimento das instituições e capacitação; relação entre o governo e o povo; boa governação e gestão dos recursos do petróleo e gás. Para cada uma destas áreas, citou as iniciativas que vinham sendo tomadas pelo governo e as carências existentes, destacando a seguir perspectivas 
futuras no caso de saída rápida da comunidade internacional. Sugeria-se, intermitentemente, que a continuidade dos apoios recebidos era condição para a chegada a bom termo das políticas públicas.

A seguir, o então representante residente do Programa das Nações Unidas para o Desenvolvimento e, ao mesmo tempo, representante especial adjunto do secretário-geral da ONU (DSRSG), Sukehiro Hasegawa, recebeu a palavra. Agradeceu a oportunidade da fala e passou a enumerar os avanços do governo no primeiro ano posterior à restauração da independência. Citou a importância do Plano de Desenvolvimento Nacional e dos Planos de Ação Anual, caracterizando-os como fundamentos para o planejamento e o orçamento dos recursos nacionais. Indicou ainda os progressos na área de infra-estrutura e no planejamento. A despeito desses elogios iniciais, destacou as dificuldades do país, sugerindo aos seus interlocutores que sem demora reorientassem suas atividades, focando prioritariamente o desenvolvimento local no interior de Timor e em práticas de boa governação.

O representante do Banco Mundial sucedeu a Hasegawa. Elogiou também os resultados alcançados pelo governo de Timor-Leste na área do planejamento, citando o Plano de Desenvolvimento Nacional, o Guia do Plano e o Plano de Estabilidade como ferramentas importantes para alocação de recursos no processo de redução da pobreza e crescimento econômico. Afirmou que a trajetória do Estado da RDTL na área do planejamento era um exemplo a ser seguido por outros países. Lançou então algumas questões para o debate, expressando as preocupações e as prioridades do Banco no processo de construção do Estado timorense.

Depois dos discursos programados, abriu-se espaço para a apresentação de questões e debates. As alocuções proferidas durante a reunião foram enunciadas pelos mais altos representantes dos países doadores. Através da fala desses atores, eram os Estados-nações que se pronunciavam. Dessa forma, por exemplo, era o Canadá que falava por meio de seu representante, assim como os EUA pela sua delegação. Por essa razão, passo a referir-me, a partir de agora, aos discursos proferidos por esses atores pela identidade do país que representavam, recurso que nos auxiliará na percepção de como a lógica da dádiva opera nesse campo. Antes, cabe ainda destacar que as manifestações dos doadores na reunião são bastante reguladas. A maioria deles reproduz, durante o ritual, discursos previamente elaborados e que, impressos, são disponibilizados ao público.

Os primeiros doadores a se manifestarem foram a Austrália e o Banco de Desenvolvimento Asiático. Ambos, depois de elogiarem os progressos alcançados pelo Estado timorense no planejamento de políticas, sugeriram a 
priorização de certas áreas de investimento público. Foi a partir da atuação do Canadá - o terceiro parceiro a se pronunciar nesta sessão - que o comportamento dos doadores começou a adquirir uma mesma forma estrutural.

O Canadá agradeceu ao governo timorense e ao Banco Mundial pela oportunidade de participação na reunião. Como os parceiros anteriores, celebrou a qualidade dos documentos distribuídos, citando o Guia do Plano. Destacou assim a competência do Estado timorense. Logo a seguir, porém, afirmou que havia muito por ser feito e que o país ainda estava dando os primeiros passos na direção do desenvolvimento. Retratou Timor-Leste como o lugar da carência, para afirmar, indiretamente, o quanto as doações são necessárias e valiosas. O doador passou então a destacar os recursos que foram oferecidos pelo Canadá ao Estado timorense desde 1999, ao mesmo tempo em que fazia sugestões com relação a como as políticas públicas deveriam ser executadas, as atividades a serem priorizadas etc. Concluiu sua fala celebrando seu compromisso com o povo timorense.

Após breves intervenções do Primeiro-Ministro e do UNIFEM (Fundo das Nações Unidas para a Mulher), os EUA se manifestaram. Este país iniciou sua locução agradecendo a oportunidade de participação na conferência e felicitando o governo pelos extraordinários progressos obtidos na transição da administração das Nações Unidas para o governo independente. Fez referência à importância dos documentos produzidos pelo governo - Plano de Desenvolvimento Nacional e Guia do Plano - classificando-os como documentos-chave para a definição da estratégia de cooperação a ser formulada pelos EUA. A seguir, destacou alguns dos problemas com os quais o Estado timorense tinha de lidar, como o grande volume de desemprego e a ineficiente prestação de serviços. Diante desses problemas, sugeriu a adoção de uma agenda política específica, na qual constasse como prioridade: 1. suporte para o estabelecimento e o desenvolvimento do setor privado como estratégia para a redução da pobreza; 2. reforço do compromisso de manutenção de um sistema político aberto e democrático.

Ainda na mesma sessão, o Japão pediu a palavra. Seguiu as estruturas de discurso anteriores, agradeceu a oportunidade de lá estar, expressando seu apoio ao Programa de Desenvolvimento Nacional. O Japão orientou seu pronunciamento no sentido de demonstrar de que maneira o país tem participado na construção e na manutenção da estabilidade de Timor-Leste. Declarou que o plano de assistência japonês prioriza políticas definidas no Plano de Estabilidade, tal como a criação de empregos para grupos vulneráveis. Afirmou que a recuperação de infra-estruturas é fundamental para o desenvolvimento do país e que o Japão continuaria a disponibilizar apoio nesta área, na qual já havia investido US\$ 500 mil. 
A seguir, Portugal se manifestou. Acompanhou a mesma fórmula discursiva do doador anterior: agradeceu e elogiou o governo da RDTL pelos esforços alcançados, para depois evidenciar algumas carências, ao mesmo tempo em que explicitava as áreas nas quais o país vinha prioritariamente cooperando - segurança, justiça e educação. Sublinhou a importância da definição de diplomas legislativos para estimular o investimento estrangeiro, bem como do fortalecimento institucional do Estado.

A Nova Zelândia sucedeu a Portugal. Como os demais parceiros, elogiou os resultados obtidos pelo governo nos últimos 12 meses de implementação do Plano de Desenvolvimento Nacional. Definiu também o seu rol de desafios-chave para o ano seguinte: estabelecimento de um sistema judicial adequado; fortalecimento de capacidades nos setores público, não-governamental e privado para prestação de serviços à população; desenvolvimento de um setor privado dinâmico; redução da pobreza. Em seguida, reiterou os compromissos que assumira em acordos bilaterais com o governo. Destacou o montante de suas doações ao país, lembrando que adicionalmente disponibilizaria para o ano fiscal 2002/3 uma contribuição de NZ\$ 500.000, elevando o total de repasses ao Estado timorense naquele ano para NZ\$ 1 milhão. Ao responder às preocupações do governo com o baixo fluxo de novos projetos, reiterou os planos para investimentos futuros nas áreas definidas como prioritárias, mostrando-se aberta a novas parcerias.

Manifestaram-se a seguir Brasil, Comunidade Européia, Finlândia, Noruega, Irlanda, China, França e Alemanha. Para uma compreensão adequada do sentido das declarações realizadas pelos doadores, é preciso situar a atmosfera em que elas foram proferidas. A cada fala, os pronunciamentos ganhavam maior vigor e agressividade. Progressivamente, cada um dos doadores fazia o seu discurso em um tom cada vez mais enfático, subindo a inflexão da voz em alguns pontos específicos das exposições, sobretudo quando se colocava em evidência os bens ofertados a Timor-Leste. A observação paralela das atuações dos parceiros na reunião indicava a existência de uma competição entre eles. Havia como que uma disputa entre os vários Estados-nações e agências da ONU sentados à mesa. Cada um destacava seus feitos em Timor-Leste, angariando com isso certo capital simbólico diante dos outros.

A reunião converteu-se assim em uma arena de disputas rituais por status político entre os doadores. Nessa guerra, a dádiva de recursos financeiros, humanos ou tecnológicos é a principal munição. Daí a necessidade de explicitar, continuamente, o perfil dos bens oferecidos por cada doador. Como produto dessa competição, estabelece-se um ranking entre os doadores, o qual define relações de precedência entre eles em alguns espaços sociais (Tomass 2001), como no jantar que o governo timorense ofereceu 
aos parceiros no dia que antecedeu à abertura da conferência. Nele, entre outras coisas, aos países que mais recursos repassam a Timor-Leste cabe a honra de se sentarem à mesa do Primeiro-Ministro.

No pronunciamento da União Européia, após o elogio aos resultados alcançados por Timor-Leste e o acréscimo dos pontos críticos para o próximo ano, ${ }^{10}$ podemos ver claramente a enunciação da dádiva:

A Comissão Européia (CE) tem trabalhado proximamente ao Timor-Leste desde 1999. Ela tem sido e continuará a ser um dos maiores doadores para este país. De 1999 a 2002, a assistência da CE totalizou 143 milhões de euros. Para o período 2002-2004, a estratégia de assistência da Comunidade Européia para Timor-Leste comprometeu-se com 46 milhões de euros, aumentando este valor para 61,5 milhões de euros, em um esforço especial da comunidade para responder às necessidades do Timor-Leste em dois setores: 1. provisão de serviços de desenvolvimento de saúde básica [...] 2. desenvolvimento rural, incluindo capacitação na sociedade civil e na administração pública. Para o ano de 2003, o apoio ao desenvolvimento do setor rural totalizará 25,5 milhões de euros. [...]

A Comissão Européia tem sido um parceiro permanente e significativo para o Timor-Leste, oferecendo importante assistência para o seu desenvolvimento. Ela espera continuar a trabalhar com este país, em seu movimento em direção ao desenvolvimento sustentável da nação.

Com uma função similar ao tanarere ${ }^{11}$ constitutivo do Kula descrito por Malinowski (1978:291), a conferência dos doadores é um ritual de exibição pública das dádivas ofertadas a Timor-Leste, no qual se definem periodicamente as relações de precedência de um doador sobre o outro. A União Européia, por exemplo, ostenta os 143 milhões de euros ofertados a Timor desde 1999. A Nova Zelândia torna público o montante de dólares disponibilizados ao país naquele período. Portugal, por sua vez, descreve os projetos em que esteve envolvido e o rumo futuro da cooperação.

A atmosfera de disputa em torno do problema de "quem dá mais" é evocada no cotidiano da administração pública pelos próprios funcionários locais, de que é exemplar o diálogo abaixo entre dois servidores do governo timorense, após participação em cerimônia de entrega de equipamentos bélicos doados pela Malásia ao Estado da RDTL, em outubro de 2003:

S: Agora que os outros países viram o que o governo da Malásia fez, vão todos querer correr atrás.

M: Vocês viram a cara do embaixador de Portugal? Estava com cara de criança, com o dedo na boca. 
S: Ah, agora Portugal vai querer doar caminhões também.

M: Aqueles? Aqueles não têm nem para eles, que dirá para doar para TimorLeste.

\section{A personalidade da dádiva}

Durante a reunião e nas atividades cotidianas de gestão da assistência externa observa-se, entre os doadores, uma estratégia de personalizar os bens ofertados a Timor-Leste, que passam a ser identificados de acordo com a origem nacional dos recursos que permitem sua aquisição. Por ocasião da conferência, as várias modalidades de cooperação são contabilizadas em termos monetários - elas são mercantilizadas - o que permite a cada doador afirmar diante dos demais, a partir de critérios equivalentes de comparação, o volume de recursos nominalmente disponibilizados ao país. No entanto, parte importante dos fundos que alcança Timor se materializa em pessoas e/ou objetos, que são caracterizados com a identidade do parceiro que o doou. A associação entre o doador e o bem ofertado é uma regra compulsória no campo da AID, e é destacada publicamente em eventos rituais e cotidianos. Dentre outras formas, ela é expressa mediante adesivos que identificam objetos doados com a procedência institucional dos fundos que permitem sua aquisição; por declarações do governo em solenidades oficiais; em documentos do Estado que relatam a execução de políticas públicas etc.

Alguns dos carros utilizados pela Presidência da República, entre 2002 e 2003, por exemplo, tinham nas portas grandes adesivos com o timbre da USAID (United States Agency for International Development). Móveis do setor de treinamento da divisão de Receita do Ministério do Plano e Finanças, por sua vez, eram selados com a marca da AusAID (Australian Agency for International Development). Computadores ofertados pelo PNUD e por outros doadores a diferentes órgãos da administração pública eram todos identificados na tampa (no caso de laptops) e na unidade de processamento de dados (no caso dos equipamentos de mesa) com grandes logotipos impressos em adesivos, os quais informavam a origem institucional dos recursos que viabilizaram a aquisição dos mesmos. Por ocasião da chegada dos geradores elétricos que, em dezembro de 2002, permitiriam que a capital do país tivesse energia 24 horas por dia, o governo preparou um evento no qual o principal homenageado seria a Noruega, doadora dos equipamentos. Ademais, uma leitura das páginas eletrônicas das principais agências do Sistema ONU em Timor revela que a origem (nacional) dos recursos financeiros e humanos que tornam possíveis a execução de projetos multilaterais é sempre destacada. 
Verifica-se, assim, um tipo de personificação da relação entre doador e a coisa doada, de maneira que o bem oferecido é, ele próprio, tomado pelos agentes deste campo (tanto doadores como beneficiários da AID) como parte da personalidade do sujeito que o doou. Neste contexto, recursos de natureza diversa, como pessoas, equipamentos tecnológicos e mesmo dinheiro, são tornados dádivas, atuando como instrumentos de construção e mediação de identidades (de pessoas e coisas) e de relações sociais.

No caso da doação de recursos humanos para programas de desenvolvimento de capacidades, essa associação é literal. Em projetos voltados para a qualificação dos funcionários públicos locais, os Estados-nações doadores levam, em geral, a Timor-Leste profissionais de sua respectiva nacionalidade. A Austrália financia a presença de assessores australianos na administração local, o Japão, de japoneses, assim como Portugal, de portugueses. Esses técnicos, por sua vez, reproduzem no país procedimentos administrativos e hábitos de trabalho que são reconhecidos como típicos de sua nacionalidade, fato que ficará evidente a seguir.

Para além de exibirem a quantidade e a qualidade das dádivas ofertadas a Timor-Leste no passado, no presente e no futuro, os doadores indicam durante a reunião a agenda política a ser priorizada pelo governo nos meses que sucedem à conferência. Lançam diferentes receitas para a construção do Estado e para a manutenção da estabilidade. Há elementos de convergência e divergência entre as propostas apresentadas. Ao se considerar, como descrevi acima, o clima de embate que informava as alocuções dos doadores, podemos ainda interpretar a reunião como um espaço onde são apresentados e disputados diferentes projetos civilizatórios para Timor-Leste, fenômeno que está em jogo no cotidiano de implementação da AID, como veremos adiante.

Apesar do significativo número de atores que tomam parte na conferência, suas atuações seguem estruturas bem definidas e de pouca variação. De um lado, há a forma típica de discurso dos doadores; de outro, aquela dos beneficiários da AID. Elas são elementos característicos da etiqueta do campo da cooperação internacional em Timor-Leste e alhures. Respeitá-la é um procedimento importante para o alcance da eficácia do evento.

Os doadores organizam seus pronunciamentos seguindo a seguinte estrutura: 1. agradecimento ao governo local; 2. elogio às ações desenvolvidas pelo Estado timorense desde a última reunião; 3. críticas à atuação do governo na gestão de políticas públicas; 4. explicitação de suas contribuições para a promoção do desenvolvimento do país; 5 . reafirmação de seu compromisso com a continuidade da assistência a Timor-Leste. As críticas alardeadas pelos parceiros às ações do governo local operam como introduções à apresentação e à celebração dos modelos de desenvolvimento histórico 
tomados como ideais segundo cada um deles. Desse modo, os doadores ostentam as dádivas ofertadas a Timor-Leste na qualidade de ingredientes fundamentais para as fórmulas de eliminação da pobreza forjadas por eles.

As alocuções das autoridades timorenses, por sua vez, seguem um enredo complementar: 1 . felicitam-se os doadores pela assistência ofertada ao país; 2 . prestam-se contas das diferentes atividades promovidas - e procedimentos adotados - pelo governo; 3. explicitam-se as limitações das políticas até então executadas; 4. apresentam-se prognósticos - geralmente pessimistas - para o futuro do país; por fim, 5. solicita-se manutenção da assistência externa ao Estado da RDTL.

Ao se colocar lado a lado cada uma das fases desses pronunciamentos, observa-se que há uma complementação entre elas. Os agradecimentos do governo são retribuídos pelos doadores com outras manifestações de gratidão. Segue-se a prestação de contas do governo timorense que, em um primeiro momento, é elogiada pelos parceiros, os quais sublinham os "importantes" passos dados na construção do Estado. O governo reconhece que, embora tenha se esforçado, ainda há muito por fazer. Os doadores concordam e esmeram-se em demonstrar o quanto Timor-Leste ainda está aquém de padrões mínimos de desenvolvimento. O governo lança suas visões sobre o futuro, retratando a catástrofe que pode acontecer em caso de retirada repentina da comunidade internacional. Os países e as agências a um só tempo fazem um balanço das doações já ofertadas a Timor e apresentam suas fórmulas de desenvolvimento histórico. O governo solicita a manutenção, senão o aumento, da ajuda oferecida a Timor-Leste. Os doadores responsabilizam-se por manter o fluxo de assistência ao país.

É importante ainda notar que em cada sessão, entre os pronunciamentos iniciais do governo e as alocuções dos doadores, manifesta-se uma das quatro instituições: Banco Mundial, Nações Unidas, Fundo Monetário Internacional ou Programa das Nações Unidas para o Desenvolvimento. Estas agências, proferindo discursos elogiosos à atuação do Estado e à condução dos projetos de desenvolvimento, atuam como fiadoras do Estado timorense diante dos doadores, garantindo aos últimos o emprego adequado dos recursos oferecidos a Timor-Leste. Isto porque, para além de monitorarem a utilização dos recursos pelo Estado - na medida em que são tomadas no campo da AID como as grandes especialistas em desenvolvimento - são elas, de fato, com exceção do FMI, as depositárias de parte significativa dos recursos oferecidos pelos doadores ao país. Tais recursos são usados na execução de programas multilaterais de desenvolvimento e ajuda humanitária.

Esse jogral ritual entre doadores e receptores da ajuda internacional põe a nu uma função crucial da conferência: ela cria condições para a ma- 
nutenção da assistência estrangeira ao país. Em uma atmosfera de intensa disputa, os doadores afirmam seu compromisso em manter a cooperação com Timor-Leste. Para tanto, o bom desempenho do Estado ao longo deste evento é fundamental e ele é mensurado, sobretudo, pela qualidade dos documentos informativos apresentados em uma pasta distribuída aos participantes momentos antes do início da conferência. Diante deste fato, faz-se necessário discutir os procedimentos envolvidos na preparação da reunião. Eles revelarão, entre outras coisas, novos aspectos da relação entre a economia da dádiva e da AID.

\section{A produção da reunião}

A preparação da conferência implica um conjunto complexo de procedimentos, os quais evidenciam traços importantes da AID em ação em Timor-Leste e alhures. Isso porque a reunião é a apoteose do investimento realizado pelos doadores e pelo governo local na boa gestão da assistência internacional. Nesse contexto, a realização adequada desse evento é tomada como um ícone da capacidade do Estado timorense em propiciar a edificação da administração pública de acordo com os critérios de boa governação existentes entre os doadores.

Durante a reunião, absolutamente todos os Estados parceiros de TimorLeste elogiaram a qualidade dos documentos distribuídos então pelo governo: o Guia do Plano, o Plano de Estabilidade, o Orçamento de Fontes Combinadas, o Perfil de Desenvolvimento de Capacidades etc. Dada a recorrência com que esses papéis são citados, podemos considerá-los personagens de suma importância nesse ritual, cujas atuações têm função decisiva para o alcance da eficácia pretendida.

O conjunto dos documentos presente na pasta entregue aos participantes responde aos objetivos que a RTLPD pretende cumprir: informa as atividades desenvolvidas pelo governo nos seis meses que antecedem a reunião; lança propostas de agenda para a construção do Estado-nação nos seis meses que se seguem à conferência e apresenta um balanço da cooperação internacional nas várias áreas de gestão do Estado, sublinhando a importância da continuidade do fluxo de recursos.

A primeira seção da pasta é composta por dois relatórios: o Documento Informativo da República de Timor-Leste e o Documento Informativo do Banco Mundial. Ambos destacam o que são denominados de progressos nas políticas de incorporação cívica, no equilíbrio fiscal e na manutenção da estabilidade do país. Trazem à tona indicadores que expressam evoluções nas 
áreas de educação, saúde, descentralização administrativa, planejamento e orçamento. A seguir figura o Guia do Plano, que é sucedido pelo Plano de Estabilidade. Ambos são roteiros para execução de políticas públicas. Eles indicam as ações e os programas que deveriam ser implementados pela administração ano a ano até 2007, conforme definidos pelos técnicos do Estado a partir de prioridades apresentadas pelo governo. Para cada atividade descrita nesses documentos são explicitados os recursos financeiros então disponíveis. Na seqüência, o Orçamento de Fontes Combinadas de TimorLeste expõe os fundos existentes para o ano fiscal 2003-4, com ênfase nos déficits com os quais o Estado se depara. O governo evidencia as lacunas orçamentárias existentes a fim de angariar mais recursos junto aos parceiros do desenvolvimento. Na seção seguinte temos o Perfil de Desenvolvimento de Capacidades dos Ministérios e, por fim, na última parte da pasta, o Perfil da Assistência Externa. Estes dois últimos documentos são especialmente expressivos para a análise aqui proposta.

O Perfil de Desenvolvimento de Capacidades dos Ministérios consiste no registro de toda a cooperação técnica prestada pelos doadores para treinamento e formação dos recursos humanos do Estado timorense. O documento indica o tipo de assistência técnica oferecida para cada agência do governo, seu período de duração e seu respectivo doador. O relatório explicita, portanto, quem são os maiores doadores para Timor-Leste nas políticas de desenvolvimento de capacidades e os diferentes tipos de dádivas ofertadas: treinamentos, assessoria técnica ou recursos para contratá-la multilateralmente etc.

O Registro da Assistência Externa, como o título evoca, apresenta o perfil da cooperação estrangeira que Timor-Leste recebeu de 1999 até o final do ano fiscal de 2003. Traça também a utilização atribuída aos recursos doados, quantificando, por doador, o destino dado aos valores nominalmente depositados em nome do país. O documento demonstra, por exemplo, que de 1999 até o final do ano fiscal 2002/03, 37 doadores, entre Estados-nações e agências multilaterais não-governamentais de cooperação, ofereceram aproximadamente US\$ 1 bilhão a Timor-Leste para ajuda orçamentária, apoio humanitário, ajuda emergencial e para o desenvolvimento. Entre as muitas tabelas presentes no documento, uma delas é fundamental: a que hierarquiza os parceiros de Timor-Leste entre si, a partir do volume de recursos disponibilizados ao país. Verifica-se dessa forma que Austrália, Japão, Portugal, União Européia e Estados Unidos eram, até então, os cinco maiores doadores do Estado timorense.

Diante da atmosfera de disputa que pauta a relação entre os parceiros na reunião, os relatórios supracitados possuem grande poder ilocucionário: 
eles inscrevem a disposição hierárquica dos doadores entre si, afirmando quais, entre eles, têm precedência sobre os demais e maior prestígio e poder na RDTL ${ }^{12}$ para influenciar as políticas adotadas pelo governo.

Neste contexto, vale notar que, até aquele período, dos cinco maiores doadores a Timor-Leste - Austrália, Japão, Portugal, União Européia e EUA quatro eram países que direta ou indiretamente haviam tido responsabilidade política pelo destino histórico do território ao longo dos séculos: Portugal foi o agente colonizador europeu por aproximadamente 430 anos; Austrália e Japão invadiram o então Timor português durante a Segunda Guerra Mundial; o Estado australiano foi um dos poucos países a reconhecer como legítima a anexação de Timor-Leste à República da Indonésia; os EUA apoiaram o regime de Soeharto na Indonésia e a ocupação militar do território timorense, fornecendo recursos bélicos para tanto. Quando tratam de dar sentido ao grande volume de recursos repassados a Timor-Leste por estes Estados, membros do governo e de organizações não-governamentais locais e internacionais recorrentemente trazem à tona os fatos supracitados. Do ponto de vista desses atores, a dádiva internacional é interpretada como um meio de se saldarem dívidas históricas, veículo através do qual certos países procuram recompor sua moral diante do mundo por ações ou omissões praticadas para com Timor-Leste.

É importante observar que os elogiados documentos apresentados aos doadores, embora tomados como produzidos pelo Estado timorense, foram de fato elaborados, em grande parte, por assessores estrangeiros remunerados com recursos da AID, lotados em diferentes instituições da administração pública local. Dessa forma, ao elogiarem copiosamente estes documentos, os doadores celebravam, em última instância, suas atuações no espetáculo da construção do Estado nacional em Timor-Leste. O louvor à performance do Ministério do Plano e Finanças na feitura de documentos de planejamento e prestação de contas era, no fundo, um elogio à intervenção dos doadores na administração pública timorense. À época, todas as posições de direção desse ministério estavam sob a responsabilidade de funcionários estrangeiros.$^{13} \mathrm{O}$ próprio sistema de orçamento tinha sido elaborado por uma missão de cooperação australiana e, até o momento da reunião aqui discutida, a responsável pelo orçamento era uma assessora cedida pelo Estado australiano.

A freqüência com que documentos de planejamento de políticas públicas e outros relatórios são citados sugere ainda que eles são componentes típicos da cultura organizacional do campo da cooperação internacional. Este último pode ser identificado não só pela agenda política que o constitui, mas também por operar por meio de formas próprias de planejar ações e 
fazer circular informações, das quais guias e receitas de políticas públicas são exemplos, símbolos da impessoalidade e da racionalidade que pretensamente caracterizam o Estado moderno. ${ }^{14}$

A contundência com que estes documentos são lembrados e os argumentos que orientam tais celebrações evidenciam que, para os atores da conferência, estes objetos são símbolos do que é tomado como um processo adequado de state formation e institutional-building. Mais do que isso, os guias de execução de políticas públicas aí presentes são considerados como o processo de construção do Estado em si. Assim, poder-se-ia dizer que mais do que símbolos eles são ícones da construção do Estado, construção esta entendida em tal contexto como a capacidade da administração pública em planejar políticas e produzir documentos..$^{15}$

Como ícones do Estado, eles têm também poder ilocucionário e perlocucionário: produzem uma realidade - um aparelho de Estado que se mostra competente na formulação das políticas públicas de acordo com os critérios de "boa governação" considerados pelos doadores - e repõem a fé da comunidade internacional ali representada nas fórmulas de desenvolvimento elaboradas e celebradas por ela. Nesse sentido, pode se pensar nessas modalidades de conferências como espaços nos quais são reproduzidos aspectos significativos das regras e dos valores que estruturam a dinâmica do campo da AID.

Os dados presentes no relatório Perfil de Desenvolvimento de Capacidades dos Ministérios permitem ainda identificar, entre outras coisas, traços da cultura burocrática que cada unidade do Estado tende a adquirir ao longo do tempo em função da influência exercida por diferentes doadores em cada uma delas. Interpretar os dados torna-se assim possível quando se revelam o modus operandi e as implicações que programas de construção de capacidades trazem para a definição do perfil institucional da administração pública local. Objetos privilegiados de doação, os projetos de desenvolvimento de capacidades são veículos por meio dos quais os doadores imprimem sua presença cotidiana, em múltiplas dimensões, no Estado timorense. Se, entre outras coisas, a Conferência dos Doadores pode ser interpretada como o espaço de celebração solene e ritual desta presença - momento legítimo de visibilização da atuação dos doadores no empreendimento de construção de um novo Estado em que, ao mesmo tempo, se reafirmam uns diante dos outros - a análise de certos aspectos dos processos que conformam as práticas de desenvolvimento de capacidades evidencia como a hegemonia dos doadores sobre a administração local é edificada e disputada dia a dia. Vejamos, a seguir, como esse fenômeno se configura. 


\section{Capacity Building e a construção do Estado em Timor-Leste}

Como afirmei acima, o sistema de doação internacional em Timor-Leste é um fato social total quando tomamos como objeto de reflexão o processo de construção do Estado. Através da disponibilização de recursos humanos, tecnológicos e financeiros, o campo da AID se faz presente em todas as faces da incipiente administração pública local. Desde 2002, parte significativa dos recursos disponibilizados tem sido aplicada em programas de desenvolvimento e/ou construção de capacidades para a formação dos servidores públicos e das próprias instituições de Estado. Esses programas são executados por meio de várias atividades: seminários, workshops, treinamentos em Timor-Leste e nos países doadores, on-job training, cursos de línguas, estudos técnicos, formulação de leis etc.

Entre 2002 e 2004, a Missão de Suporte das Nações Unidas em TimorLeste (UNMISET) e o Programa das Nações Unidas para o Desenvolvimento (PNUD) gerenciavam dois grandes projetos - o Programa dos 100 Postos de Estabilidade e o Programa dos 200 Postos de Desenvolvimento, respectivamente - que propiciavam a contratação de assessores técnicos estrangeiros. Distribuídos em várias instituições do Estado, esses conselheiros internacionais tinham por função, com diferentes graus de prioridade para cada caso, elaborar instrumentos de estruturação, gestão, implementação e monitoramento de políticas públicas - como legislações, regulamentos, programas de desenvolvimento etc - que normalizassem o funcionamento do Estado, e capacitar contrapartes locais que, em médio prazo, deveriam assumir plenamente as funções de administração pública. Muitos conselheiros eram responsáveis diretos pela edificação e administração de importantes órgãos de soberania do país, como a Autoridade Bancária e de Pagamentos (instituição que corresponde ao Banco Central do país), o Tribunal de Recurso (tribunal de mais alto nível na hierarquia do Poder Judiciário local), diretorias dos Ministérios da Justiça, do Plano e Finanças etc. Outros, por sua vez, tinham por tarefa elaborar os documentos presentes na pasta entregue aos doadores por ocasião da Reunião de Timor-Leste com os Parceiros do Desenvolvimento.

Contratados pelas Nações Unidas e por agências bilaterais de cooperação, esses assessores vinham dos mais diferentes países: Portugal, Austrália, Brasil, Índia, Paquistão, Sri Lanka, Irlanda, Espanha, Equador, Filipinas, Nova Zelândia, África do Sul, Jamaica, Estados Unidos e outros. Como iriam trabalhar diretamente na formação do Estado timorense, priorizava-se a contratação de técnicos com grande experiência em administração pública em seus países de origem ou além-mar. 
Em sua atuação no processo de edificação do Estado local, a maioria dos assessores tendia a reproduzir in locu os princípios de fundação e gestão da máquina pública existentes em seu país de origem ou naqueles em que adquiriu sua maior capacitação profissional. É nesse sentido que se pode compreender, por exemplo, o que leva o sistema de orçamento de TimorLeste a ser tão semelhante àquele da Austrália, uma vez que foi elaborado por assessores técnicos formados e com experiência no Estado australiano. A mesma rede de causalidade pode ser utilizada para explicar a semelhança entre o Código de Processo Penal timorense com o que é vigente em Portugal: ele foi elaborado por uma equipe de juristas portugueses. É, pois, nesse mesmo registro que se compreende o fato de a Constituição timorense ser tão similar à portuguesa. A lei máxima da RDTL foi construída com base em um projeto de lei apresentado por um magistrado português e com a colaboração de uma grande missão bilateral portuguesa, enviada pelo Parlamento lusitano a pedido de autoridades timorenses.

Embora tenham sido privilegiados acima casos que abordam de que maneira a origem nacional dos assessores técnicos contratados bi ou multilateralmente condiciona os contornos jurídicos que o Estado timorense tem ganhado ao longo do tempo, é preciso considerar que eles atuam como mediadores em outras faces do processo civilizatório em curso no país. As formas como os técnicos estrangeiros treinam os servidores locais em certas rotinas burocráticas, como formulação de documentos oficiais de tipo memorando ou ofício, e o idioma que utilizam para tanto estão relacionados ao seu país de origem ou ao território nacional no qual adquiriram sua experiência de formação e/ou atuação profissional mais expressiva.

Raros são os assessores estrangeiros que se dispõem a aprender tétum, a língua veicular de Timor-Leste. Por isso, tendem a desempenhar suas funções utilizando a língua inglesa ou a portuguesa, no caso dos assessores de origem lusófona, a despeito das dificuldades que tal procedimento possa trazer ao processo de capacitação. Dessa forma, funcionários públicos timorenses - direta ou indiretamente subordinados a um assessor australiano que trabalha em língua inglesa e que tenha tido, inclusive, função importante para a edificação institucional da repartição do Estado na qual está lotado provavelmente estarão lidando com rotinas de gestão da administração pública típicas de um sistema de Common Law, e comunicando-se, oral e graficamente, com freqüência em língua inglesa. Já diante de assessores portugueses, a tendência é similar em forma, mas distinta em conteúdo: servidores timorenses subordinados a assessores lusófonos tendem a utilizar a língua portuguesa e a reproduzir rotinas administrativas típicas do que talvez possamos chamar de matriz lusitana. 
Estes casos indicam como práticas de assistência técnica internacional operam como instrumentos políticos nos processos de formação de identidades estatais em países de independência recente. Eis o que nos permite interpretar os dados apresentados em documentos, como o Perfil de Desenvolvimento de Capacidades e o Registro da Assistência Externa, como indicadores da hegemonia que diferentes doadores e suas respectivas culturas nacionais exercem nas diversas instituições que constituem a incipiente administração pública timorense. Assim, é bastante provável que em órgãos com forte presença de assessores de origem de países da Commonwealth (Austrália, Canadá, Quênia, Índia, África do Sul, entre outros) os instrumentos burocráticos de gestão do aparelho do Estado e, por conseqüência, de domesticação da conduta dos timorenses, e a língua de trabalho utilizada sejam de inspiração anglo-saxã. Neste contexto, os assessores acabam tendo papel importante no sucesso ou no fracasso da implementação das línguas oficiais do país, o português e o tétum, participando ativamente do processo de nation building. Desse modo, desde 1999, Timor-Leste tem se transformado em palco para disputas entre diferentes projetos civilizatórios existentes entre diferentes agentes do campo da AID.

Para além das implicações técnicas que essa babel burocrática e lingüística traz para a edificação de uma máquina estatal minimamente coerente e articulada, é importante notar que no dia-a-dia da construção do Estado há uma politização destas diferentes culturas administrativas, tanto por parte dos assessores estrangeiros como de suas contrapartes timorenses, os beneficiários, receptores da AID. Entre os internacionais, as disputas polarizam-se principalmente entre projetos anglófonos e lusófonos para a construção do Estado.

Muitos assessores de origem anglófona consideravam inadequada a então presença expressiva de conselheiros da CPLP (Comunidade dos Países de Língua Portuguesa) atuando no Estado timorense. Segundo muitos eles, Portugal e suas ex-colônias teriam uma administração pública ineficiente, cujo modus operandi não deveria ser reproduzido, portanto, em Timor-Leste. A eficiência dos assessores lusófonos e das técnicas ou legislações empregadas ou sugeridas por eles para o Estado timorense era muitas vezes questionada pelos advisors anglófonos, avaliada em função da maneira como estes últimos atribuíam sentido ao desenvolvimento histórico do Estado português e de seu antigo império.

As intervenções dos assessores anglófonos na administração pública local, por sua vez, não eram bem vistas por muitos conselheiros de origem portuguesa e/ou de países de tradição administrativa latina, como aqueles originários da América Central e do Sul. Retratados como inflexíveis e exces- 
sivamente burocráticos, os assessores anglófonos eram caracterizados como impositivos por grande parte dos latinos, incapazes de perceberem e de respeitarem as particularidades da cultura timorense e do que era considerado pelos portugueses como questão fundamental do projeto de construção nacional de Timor-Leste: a lusofonia. Os portugueses, particularmente, contrapunham-se aos anglófonos apresentando-se como mais abertos ao contato e à convivência com a diversidade, "de que seriam testemunhas, sobretudo, os brasileiros, produtos de uma miscigenação ímpar entre europeus, ameríndios e africanos propiciada pela colonização lusitana na América", nos termos de alguns deles. Em função desta denominada tradição e também do fato de terem atuado durante mais de 400 anos como potência colonizadora de Timor-Leste, os portugueses estariam, segundo eles próprios, mais aptos a assumir o papel de mentores do processo de construção do Estado local.

Observa-se, portanto, que na dinâmica do campo da AID em Timor-Leste a atuação dos recursos humanos estrangeiros doados temporariamente ao país - cujas ações se materializam em propostas e práticas de políticas públicas - é abordada em função da maneira como diferentes grupos avaliam o processo de desenvolvimento histórico e a identidade do país de origem desses técnicos. Dessa forma, o valor do bem doado (no caso, o assessor técnico) é mensurado também em função de como sua origem nacional é percebida pelos diferentes agentes do campo. Assim, pessoas (os assessores técnicos), instituições (os países doadores) e fatos (práticas de capacitação e projetos de políticas públicas) misturam-se.

\section{O espírito das coisas e a especialização da dádiva}

A discussão acima indica de que maneira os programas de capacitação podem funcionar como modos de relacionar coisas, pessoas e instituições. Em última instância, este mecanismo está indissociado de um processo de construção de hegemonia. Nestes projetos, a disputa pela hegemonia entre os doadores é materializada na atuação dos assessores internacionais ofertados por eles, mediante as práticas de treinamento e as propostas de estruturação política e jurídica do Estado timorense apresentadas pelos conselheiros. Veja-se, pois, que esses fenômenos (legislações, língua de trabalho, políticas públicas, padrões de documentos etc) estão longe de ser percebidos como puramente técnicos. A eles se associa uma série de valores simbólicos e a própria identidade do país, que propicia suas respectivas existências. Eles são experimentados, do ponto de vista nativo, como fortemente associados ao país de origem do assessor que os propõe e os executa. 
Se o vínculo entre a coisa doada e a identidade do doador é mais evidente em projetos que envolvem recursos humanos, isto também pode ser observado de forma mais sutil quando analisamos as prioridades de cooperação de diferentes parceiros. Tipos diversos de políticas executadas por variados doadores no campo da AID expressam sua visão de mundo e interesses que se manifestam em projetos civilizatórios distintos. Assim, cada país privilegia modalidades específicas de projetos, especializando-se em áreas distintas de cooperação, as quais estão vinculadas à própria imagem que querem cultivar de si para o mundo.

Essa "especialização da dádiva" remete, de algum modo, a ideologias nacionais. Vinculada a narrativas de formação nacional, a especialização da dádiva de um país expressa a imagem e os interesses que ele busca projetar de si mesmo. A especialização é produto das diferentes prioridades de cooperação que, por sua vez, são definidas em diálogo com os interesses dos parlamentos e dos governos que gerem o Estado de cada país doador e com os projetos de narração de construção nacional alimentados por eles. O exemplo de Portugal é um caso interessante deste fenômeno. Por que Portugal tem tantos projetos na área da língua portuguesa? Isto está relacionado com o fato de a questão da língua portuguesa ter se tornado para Portugal uma fonte de identidade nacional e um instrumento para a construção de vínculos entre os territórios de seu antigo império colonial. Não por acaso, a denominação do bloco político formado por Portugal e seus antigos territórios ultramarinos é Comunidade dos Países de Língua Portuguesa (CPLP).

Ademais, quando falo da identidade das coisas, quero enfatizar que as doações neste campo não têm somente valor em si. O valor da doação é muitas vezes um elemento relacionalmente estabelecido, levando-se em conta o perfil e os interesses de quem dá e, especialmente, de quem recebe. Assim, por exemplo, os projetos desenvolvidos pelo Brasil e por Portugal são muito valorizados pela elite do Estado timorense atualmente no poder, na medida em que contribuem para a consolidação do projeto de construção nacional alimentado por ela e para o enlaçamento de Timor-Leste à CPLP, à diferença das doações de países de matriz anglófona, sobretudo aquelas que se originam da Austrália, que disputa com o país direitos de exploração de recursos petrolíferos existentes nas adjacências da ilha.

Nesse sentido, parece ser o valor de vínculo o que mais importa no reconhecimento local de um projeto de cooperação. A conseqüência direta disto é que a percepção (o reconhecimento) de quem recebe conta muito para a definição do valor moral da doação feita e, conseqüentemente, para o prestígio e a imagem de quem doa em espaços glocalizados de relações políticas, como em países altamente dependentes da AID, de que Timor-Leste é um 
caso exemplar. Este fenômeno vai ao encontro da sugestão de L. Cardoso de Oliveira (2005:4) a respeito do lugar do reconhecimento nas relações sociais. Embora tratando de objetos etnográficos bastante distintos, o autor afirma que o reconhecimento é a contraface do hau em relações de reciprocidade.

\section{Considerações finais}

Iniciei este texto abordando aspectos do comportamento de determinados países diante das destruições causadas pelos tsunamis no sul da Ásia, em dezembro de 2004. Vimos que diante do constrangimento causado pelas afirmações de Jan Egeland, os EUA e outros países aumentaram vertiginosamente sua ajuda humanitária. Entre outras coisas, esse evento demonstra como a obrigação de dar é uma força moral que se impõe a diferentes agentes, os quais a subvertem em condição para o exercício e a negociação de relações políticas. Nesse sentido, não parece ser acaso que os maiores doadores para Timor-Leste, com exceção da Comunidade Européia, sejam os países que tiveram responsabilidade direta pelo destino histórico do território. Dessa forma, a AID tem se convertido ao longo do tempo em um campo onde os Estados-nações realizam a performance de suas catarses históricas e (re)constroem suas identidades diante do mundo.

As políticas de assistência internacional são também utilizadas como expediente para a construção de hegemonia dos doadores em diferentes países. A discussão realizada acima a respeito dos projetos de desenvolvimento de capacidades demonstra como a dominância de diferentes doadores na administração local é cotidianamente disputada por meio dos recursos humanos e técnicos que são ofertados ao Estado. Ocorre então uma especialização das políticas de doação entre os parceiros, que passam a ofertar bens e serviços que expressam a maneira como cultivam a sua identidade, o seu espírito para o mundo. A identidade do doador é ostensivamente destacada nas modalidades de troca existentes no campo da AID. É como se o espírito do doador circulasse através dos recursos concedidos ao beneficiário.

Ademais, as dádivas ofertadas pelos doadores enlaçam Timor-Leste (como qualquer outro país dependente da AID) em relações de obrigação, que se manifestam em espaços globais de negociação política, como a Assembléia Geral da ONU, por exemplo. Nessas arenas, é quase impossível que Timor-Leste sustente posições distintas daquelas de seus grandes doadores sem sofrer qualquer tipo de sanção no campo da AID.

A assistência internacional prestada potencializa ainda os doadores em sua capacidade de exercer influência sobre a condução da política interna 
do país. Em cenários de crise ou de grandes desafios políticos, os maiores parceiros do desenvolvimento são muitas vezes convocados para reuniões com o governo.

As doações figuram também como fonte de prestígio e poder de seus agentes em arenas regionais de negociação, como a ASEAN (Association of Southeast Asian Nations), prestígio este que tem reverberações em palcos globais de atuação política. A economia da dádiva está longe, portanto, de ser um veículo de gestão de relações políticas, somente operante em microssociedades.

Por fim, vimos que a conferência é sobretudo um espaço no qual diferentes atores celebram suas próprias intervenções na edificação da administração pública local. Nesse sentido, talvez possamos afirmar que a maior contradádiva de Timor-Leste aos seus parceiros seja a de se colocar como um espaço em que valores caros aos seus doadores - de que os mitos ocidentais de boa sociedade são expressão: os ideais de igualdade, liberdade e democracia - possam mais uma vez ser cultivados no processo de construção de um novo Estado-nação.

Recebido em 20 de outubro de 2006

Aprovado em 14 de novembro de 2007

Kelly Cristiane da Silva é professora do departamento de antropologia da UnB. E-mail: kellysa@uol.com.br.

\section{Notas}

${ }^{1}$ A discussão das funções atribuídas às políticas de cooperação internacional pode ser realizada de vários ângulos: podem ser privilegiados, por exemplo, os debates parlamentares que se constroem em torno delas em muitos dos países em que este tema já se consolidou como uma questão de políticas públicas, até a maneira como elas são experimentadas por seus beneficiários de ponta. De um extremo a outro, é preciso lembrar que as práticas de cooperação internacional são diversamente interpretadas e apropriadas pelos poderes executivos de cada Estado-nação doador, por suas respectivas agências de cooperação internacional, pelos funcionários destas agências, pelas elites dos Estados beneficiários, entre outros atores. Assim, a pers- 
pectiva de análise aqui adotada privilegia apenas uma das arenas em que a gestão deste fenômeno se dá.

${ }^{2}$ Para efeito da análise da Reunião de Timor-Leste com os Parceiros do Desenvolvimento, oriento-me pela definição de rituais tal como apresentada por Tambiah (1985). Para ele, os rituais são sistemas simbólicos de comunicação constituídos por seqüências ordenadas de palavras e atos que, fazendo uso de múltiplos meios, guardam graus definidos de formalidade, estereótipo, condensação e redundância. A análise semiótica dos rituais inspira-se em três preceitos principais: 1. deve analisar-se os rituais como eventos felizes ou infelizes, no sentido de cumprirem ou não as funções às quais se propõem; 2 . deve atentar-se para as várias funções de cada ato ritual segundo os critérios de classificação dos atos lingüísticos apresentados por Jakobson (1965); por fim, 3. deve observar-se os vários tipos de signos constitutivos do ritual, segundo uma das tricotomias apresentada por Pierce (1999), qual seja, de que os signos podem ser ícones, índices ou símbolos.

${ }^{3}$ Para além de centenas de mortes, o desmonte da administração estatal indonésia em Timor-Leste, em 1999, desencadeado após o resultado do referendo promovido pela ONU — no qual 78,5\% da população manifestaram-se pela independência do território com relação à República da Indonésia - levou à destruição de aproximadamente 70\% das infra-estruturas existentes no então Timor Timur (World Bank 1999), ao deslocamento forçado de $75 \%$ da população (idem) e à fuga em massa dos recursos humanos de alto escalão da administração provincial oriundos de outras ilhas do arquipélago. Diante do vácuo de autoridade existente, a ONU instalou uma inédita missão de administração estatal, a UNTAET (United Nations Transition Administration in East Timor). Em 2002, com a restauração da independência, as Nações Unidas reformularam sua missão no país, recolhendo-se do palco aos bastidores. A UNTAET cedeu lugar à UNMISET (United Nations Mission of Support in East Timor). Formada por três componentes principais - militar, policial e civil — a UNMISET tinha por função dar suporte técnico ao Estado da RDTL, propiciando o fortalecimento institucional dos aparelhos administrativos e de segurança timorenses. Para tanto, a execução de políticas de desenvolvimento de capacidades era uma das principais estratégias adotadas. O mandato da UNMISET encerrou-se em maio de 2005. A missão foi substituída pelo Escritório das Nações Unidas em Timor-Leste (UNOTIL).

${ }^{4}$ Ao longo dos últimos anos, a ajuda internacional à reconstrução de Timor-Leste tem sido depositada em fundos como o CFET (Consolidated Fund for East Timor) e o TFET (Trust Fund for East Timor), ou diretamente em contas das missões da ONU e de suas agências e do governo timorense. Os fundos supracitados são administrados por agências específicas e têm objetivos próprios, bem como cada uma das missões que a ONU já instalou no país. O TFET, por exemplo, está sob a tutela do Banco Mundial e do Banco de Desenvolvimento Asiático, que investem em projetos de desenvolvimento e de reconstrução de infra-estruturas do país. Para uma análise da aplicação de cada um desses fundos, ver publicações da organização La'o Hamutuk disponíveis no endereço: www.laohamutuk.org. 
${ }^{5}$ Parte importante dos fundos formalmente doados ao Estado timorense pelos parceiros do desenvolvimento era de fato depositada em contas do Banco Mundial e de outras agências multilaterais para administração de projetos executados no país. Sua utilização é, portanto, tutelada pelos próprios doadores. Além disso, outra fração significativa dos recursos sequer chega ao país, uma vez que é aplicada pelos doadores no financiamento da gestão da burocracia da AID.

${ }^{6}$ Para Appadurai (1986), a circulação de objetos e serviços nas sociedades se faz através de regimes diferenciados de valor, que se impõem aos bens de maneira distinta no tempo e no espaço ao longo de suas respectivas histórias de vida. Ele sugere a existência de pelo menos três regimes de valor particulares: 1. o regime de escambo; 2. o regime de mercado; e 3. o regime da dádiva. O regime de escambo é definido pelo autor como aquele em que as trocas se dão sem a mediação de moedas, com maior redução possível dos investimentos pessoais e sociais envolvidos na troca. O regime de mercado é caracterizado quando o valor de um bem é calculado em função de seu valor de troca em linguagem monetária. Já no regime da dádiva, o valor dos bens é calculado em função de como a eles se relacionam identidades pessoais e coletivas, de modo que seus valores estão associados aos vínculos através dos quais circulam.

${ }^{7}$ O sistema de doação a Timor-Leste, tal como se configurava entre 2002 e 2003, nasceu em 1999, quando o Escritório das Nações Unidas para Coordenação de Assuntos Humanitários (OCHA) lançou um apelo junto a governos e agências de desenvolvimento de todo o mundo para arrecadação de fundos para a reconstrução do país, o Consolidated Inter-Agency Appeal (CAP). Posteriormente, na conferência de doadores em Tóquio, criou-se o CFET (Consolidated Fund for East Timor) e o TFET (Trust Fund for East Timor) e definiu-se o destino de parte dos recursos prometidos. Atualmente, a DPGAE (Divisão do Plano e de Gestão da Assistência Externa) é a agência do governo responsável pela administração da cooperação técnica e humanitária internacional na estrutura do Estado timorense.

${ }^{8}$ De 1999 a 2002, as conferências com os doadores foram organizadas pelo Banco Mundial. Da restauração da independência de Timor-Leste até meados de 2004, esse trabalho foi realizado por meio de parcerias entre o governo local e o Banco Mundial. Desde então, o Estado timorense é responsável pelo evento.

${ }^{9}$ São convidados para a RTLPD todos os parceiros do desenvolvimento que em algum momento, a partir de 1999, disponibilizaram recursos para a reconstrução do país. Dessa forma, têm assento na mesa principal do evento Estados-nações, agências multilaterais de desenvolvimento, bancos multilaterais de desenvolvimento etc. Na reunião de maio de 2003, participaram da conferência os seguintes doadores: Austrália, Brasil, China, União Européia, França, Alemanha, Irlanda, Japão, Coréia, Malásia, Nova Zelândia, Noruega, Portugal, Espanha, Tailândia, Reino Unido, Estados Unidos da América, Organização Mundial da Migração (IOM), Organização Mundial do Trabalho (OIT), Organização Mundial da Saúde (OMS), Organização das Nações Unidas para Educação, Ciência e Cultura (UNESCO), Escritório das Nações Unidas para Serviços de Projeto (UNOPS), Fundo das Nações Unidas para 
a Mulher (UNIFEM), Fundo das Nações Unidas para População (UNFPA), Fundo das Nações Unidas para a Infância (UNICEF), Programa das Nações Unidas para o Desenvolvimento (UNDP), Missão de Suporte das Nações Unidas em Timor-Leste (UNMISET), Fundo Monetário Internacional (IMF), Banco de Desenvolvimento Asiático (ADB) e Banco Mundial (WB).

10 "Queremos nos congratular com o progresso feito pelo governo até o momento, especialmente na criação de instituições, bem como no estabelecimento de uma estrutura legislativa e de sistemas de gestão. Estas oportunas conquistas são prérequisitos para uma prestação de serviços eficiente, igualitária e favorável aos mais pobres, e indicam que Timor-Leste está claramente comprometido com o Plano de Desenvolvimento Nacional. [...] Muita coisa resta a ser feita. Os setores judiciário, de segurança pública e financeiro, todos eles importantíssimos, parecem desenvolver-se lentamente. A lenta execução orçamentária tem um impacto negativo sobre a ajuda financeira dada pela CE e traz à tona a questão da limitada capacidade operacional de Timor-Leste para efetivamente absorver no futuro grandes entradas de recursos financeiros. Deve-se prestar atenção à transparência e à eficiência administrativa e financeira".

${ }^{11}$ Malinowski (1978:291) define o tanarere como um episódio do Kula no qual se expõem competitivamente os produtos obtidos na troca.

${ }^{12}$ Locução, ilocução e perlocução são qualidades de determinados enunciados tal como classificados por Austin (1999). Locução é um tipo de enunciado com qualidade referencial; ilocução é um tipo de enunciado que, se proferido em condições adequadas, faz algo ao mesmo tempo em que a sentença é anunciada. Austin denomina este último de performative utterances. Por fim, as sentenças perlocucionárias são aquelas das quais se obtêm efeitos que não estavam previstos no ato da fala.

${ }^{13}$ Refiro-me aqui aos postos da administração pública denominados de Direções Nacionais que, na hierarquia do funcionalismo local, correspondem a posições de nível 6. Trata-se de posições de segundo escalão.

${ }^{14}$ Para uma discussão sistemática de aspectos da cultura burocrática e organizacional do campo da AID, ver Stirrat 2000.

${ }^{15}$ Utilizo os termos ícone e símbolo no sentido proposto por Pierce (1999). Ícone é um signo cujo potencial significativo advém da relação de similaridade com a coisa representada. Já os símbolos são signos cuja capacidade representativa advém de uma relação estabelecida com a coisa representada por força de convenção. 


\section{Referências bibliográficas}

APPADURAI, Arjun. 1986. "Introduction". In: The social life of things. Commodities in cultural perspective. Cambridge: Cambridge University Press. pp. 3-63.

AUSTIN, John L. 1999. How to do things with words. Londres: Harvard University Press.

CAILLÉ, Alain. 2002. Antropologia do dom: o terceiro paradigma. Petrópolis: Vozes.

CARDOSO DE OLIVEIRA, Luis R. 2005. "Direitos, insulto e cidadania. (Existe violência sem agressão moral?)". Série Antropologia, 371:1-16.

GODBOUT, Jacques T. 1999. O espírito da dádiva. Rio de Janeiro: Editora Fundação Getúlio Vargas.

"GOVERNOS disputam posição de maior doador". 2005. Folha de Sáo Paulo, São Paulo, Caderno Mundo, 6 de janeiro, p. A10.

"GRUPOS de ajuda humanitária dos EUA recebem 739 milhões de dólares". 2005. Folha de São Paulo, São Paulo, 12 de setembro.

HANCOCK, Graham. 1989. Lords of poverty. Nova York: Atlantic Monthly Press.

JAKOBSON, Roman. 1965. Lingüística e comunicação. São Paulo: Cultrix.

LA'O HAMUTUK. 2001. The La'o Hamutuk Bulletin, 2(1-2).

LÉVI-STRAUSS, Claude. 1982. As estruturas elementares do parentesco. Petrópolis: Vozes.

MALINOWSKI, Bronislaw K. 1978. Os argonautas do Pacífico Ocidental: um relato do empreendimento e da aventura dos nativos nos arquipélagos da Nova Guiné, Melanésia. São Paulo: Abril Cultural.

MASON, Edward. 1964. Ajuda estrangeira e política estrangeira. Rio de Janeiro: Editora Presença.

MAUSS, Marcel. 1974. "Ensaio sobre a dádiva". In: Sociologia e antropologia, vol. II. São Paulo: Editora Pedagógica e Universitária Ltda. pp. 37-184.

"ONU arrecada 70\% da verba emergencial". 2005. Folha de São Paulo, São Paulo, Caderno Mundo, 12 de janeiro, p. A11.

PIERCE, Charles. 1999. Semiótica. São Paulo: Editora Perspectiva.

TAMBIAH, Stanley. 1985. Culture, thought and social action. Boston: Harvard University Press.

TOMASS, Lea Maria. 2001. Diferença e igualdade entre os Estados. Uma etnografia da precedência nas relações diplomáticas. Dissertação de mestrado, Universidade de Brasília. Mimeo.

SILVA, Kelly Cristiane da. 2004. Paradoxos da autodeterminação. A construção do Estado-nação e práticas da ONU em Timor-Leste. Tese de doutorado, Universidade de Brasília. Mimeo.

STIRRAT, Roderick. L. 2000. "Cultures of consultancy". Critique of Anthropology, 20(1):31-46.

WORLD BANK. 1999. Joint Assessement Mission Report. S.l.. Mimeo. 
Resumo

Este texto propõe que aspectos relevantes das práticas de cooperação internacional para o desenvolvimento são melhor compreendidos à luz do regime da dádiva. Para tanto, confrontam-se dados etnográficos relacionados com o modus operandi do campo da AID em TimorLeste com os legados de Marcel Mauss e a recente produção do M.A.U.S.S. Indica-se que as políticas internacionais de doação são veículos privilegiados de construção de hegemonia em arenas glocalizadas de negociação, mediante as quais diferentes atores constroem identidades e vínculos de aliança, honra e precedência. Neste debate, sugere-se que a maior contradádiva de Timor-Leste à comunidade internacional seja a de se colocar como um instrumento por meio do qual valores caros aos seus doadores, expressos nos mitos ocidentais de boa sociedade, possam mais uma vez ser cultivados no processo de edificação de um novo Estado-nação.

Palavras-chave: Cooperação internacional, Dádiva, Estado-nação, Política, Timor-Leste
The article proposes that some of the key practices in the area of international cooperation for development can be better understood in terms of a gift regime. To this end, it compares ethnographic data relating to the modus operandi of the aid sector in East Timor with the legacy of Marcel Mauss and the recent production of M.A.U.S.S.. International aid policies are shown to be important means for establishing hegemony in negotiation spaces in which different actors construct identities and relations of alliance, honour and precedence. In this debate, it is argued that East Timor's biggest countergift to the international community has been to function as an instrument through which values cherished by aid donors, expressed in Western myths of good society, can once again be cultivated in the process of building a new nation state.

Key words: International Cooperation, Gift, Nation State, Politics, East Timor 